\title{
Differences in neurosurgical treatment of intracerebral haemorrhage: a nation-wide observational study of 578 consecutive patients
}

\author{
Andreas Fahlström ${ }^{1} \cdot$ Lovisa Tobieson $^{2} \cdot$ Henrietta Nittby Redebrandt $^{3} \cdot$ Hugo Zeberg $^{4} \cdot$ Jiri Bartek Jr $^{5,6,7}$. \\ Andreas Bartley ${ }^{8}$ - Maria Erkki ${ }^{9}$ - Amel Hessington ${ }^{1} \cdot$ Ebba Troberg $^{3} \cdot$ Sadia Mirza $^{5} \cdot$ Parmenion P. Tsitsopoulos $^{1}$. \\ Niklas Marklund ${ }^{1,2,3}$
}

Received: 18 December 2018 / Accepted: 13 February 2019 / Published online: 15 March 2019

(C) The Author(s) 2019

\begin{abstract}
Background Supratentorial intracerebral haemorrhage (ICH) carries an excessive mortality and morbidity. Although surgical ICH treatment can be life-saving, the indications for surgery in larger cohorts of ICH patients are controversial and not well defined. We hypothesised that surgical indications vary substantially among neurosurgical centres in Sweden.

Objective In this nation-wide retrospective observational study, differences in treatment strategies among all neurosurgical departments in Sweden were evaluated.

Methods Patient records, neuroimaging and clinical outcome focused on 30-day mortality were collected on each operated ICH patient treated at any of the six neurosurgical centres in Sweden from 1 January 2011 to 31 December 2015.

Results In total, 578 consecutive surgically treated ICH patients were evaluated. There was a similar incidence of surgical treatment among different neurosurgical catchment areas. Patient selection for surgery was similar among the centres in terms of patient age, pre-operative level of consciousness and co-morbidities, but differed in ICH volume, proportion of deep-seated vs. lobar ICH and pre-operative signs of herniation $(p<.05)$. Post-operative patient management strategies, including the use of ICP-monitoring, CSF-drainage and mechanical ventilation, varied among centres $(p<.05)$. The 30-day mortality ranged between 10 and $28 \%$.

Conclusions Although indications for surgical treatment of ICH in the six Swedish neurosurgical centres were homogenous with regard to age and pre-operative level of consciousness, important differences in ICH volume, proportion of deep-seated haemorrhages and pre-operative signs of herniation were observed, and there was a substantial variability in post-operative management. The present results reflect the need for refined evidence-based guidelines for surgical management of ICH.
\end{abstract}

Keywords Intracerebral haemorrhage $\cdot$ Surgery $\cdot$ Guidelines · Craniotomy $\cdot$ External ventricular drain · Intraventricular haemorrhage

Andreas Fahlström and Lovisa Tobieson contributed equally to this work.

This article is part of the Topical Collection on Vascular Neurosurgery Other

Andreas Fahlström

andreas.fahlstrom@akademiska.se

1 Department of Neuroscience, Neurosurgery, Uppsala University, Uppsala University Hospital, SE-751 85 Uppsala, Sweden

2 Department of Neurosurgery and Department of Clinical and Experimental Medicine, Linköping University, Linköping, Sweden

3 Department of Clinical Sciences Lund, Neurosurgery, Lund University, Skane University Hospital, Lund, Sweden

4 Department of Neuroscience, Karolinska Institutet, Stockholm, Sweden
5 Department of Medicine and Clinical Neuroscience, Karolinska Institutet, Stockholm, Sweden

6 Department of Neurosurgery, Karolinska University Hospital, Stockholm, Sweden

7 Department of Neurosurgery, Copenhagen University Hospital Rigshospitalet, Copenhagen, Denmark

8 Department of Clinical Neuroscience, Neurosurgery, University of Gothenburg, Sahlgrenska Academy, Sahlgrenska University Hospital, Gothenburg, Sweden

9 Department of Clinical Neuroscience, Neurosurgery, Umeå University, Umeå University Hospital, Umeå, Sweden 


$\begin{array}{ll}\text { Abbreviations } \\ \text { EVD } & \text { external ventricular drain } \\ \text { ICH } & \text { intracerebral haemorrhage } \\ \text { CSF } & \text { cerebrospinal fluid } \\ \text { ICP } & \text { intracranial pressure } \\ \text { RCT } & \text { randomised controlled trial } \\ \text { CT } & \text { computed tomography } \\ \text { ICD-10 } & \text { International Statistical Classification of } \\ & \text { Diseases and Related Health Problems - Tenth } \\ & \text { Revision } \\ \text { MRI } & \text { magnetic resonance imaging } \\ \text { DSA } & \text { digital subtraction angiography } \\ \text { HC } & \text { hydrocephalus } \\ \text { IVH } & \text { intraventricular haemorrhage } \\ \text { GCS-M } & \text { Glasgow Coma Scale Motor score } \\ \text { LOS } & \text { length of stay } \\ \text { NCC } & \text { neurocritical care } \\ \text { NOAC } & \text { non-vitamin K anticoagulant drug }\end{array}$

\section{Introduction}

Spontaneous supratentorial intracerebral haemorrhage (ICH) comprises approximately $10-20 \%$ of all stroke [10], with an annual incidence of around 20 cases per $100,000[2,4]$. Mortality rate reaches $40 \%$ at 1 month, $54 \%$ at 1 year and only $12-39 \%$ of the survivors reach functional independence [4]. Negative prognostic factors include large ICH volume, non-lobar location, intraventricular extension of haemorrhage, poor neurological status and high age [3, 18, 35, 42].

Treatment for ICH encompasses both medical and surgical strategies $[8,50,51]$. The rationale for surgical intervention is reduction of mass effect and elevated intracranial pressure (ICP), as well as a possible improvement in perihaemorrhagic brain tissue environment by enhancing cerebral perfusion and by removing neurotoxic substances $[24,29,34,45,48]$. Whether or not surgery improves the outcome of patients with spontaneous supratentorial ICH and is superior to best medical treatment is a subject of intense debate and controversy [11]. There are a number of small $[6,7,15,21,33,37,44,52]$ and two large $[30,32]$ randomised controlled trials (RCT) of surgically treated ICH patients showing varying mortality and morbidity. Neither of the two large RCTs conducted in recent years, STICH [30] and STICH II [32], showed significant differences between early surgery versus best medical treatment, although patient inclusion criteria and large cross-over between treatment groups limit the generalizability of the results. Additionally, two meta-analyses of such RCTs [14, 39] both found a small but significant benefit of surgical treatment over best medical management, albeit with large data heterogeneity.
Guidelines defining indications for surgical treatment are still lacking [18, 42] which plausibly opens up for large variation in the treatment provided to ICH patients [13]. Moreover, to date, treatment differences among neurosurgical centres have not been thoroughly evaluated [11].

There are national and regional stroke guidelines in Sweden [41], in line with the American and European guidelines $[18,42]$. However, these address mainly the medical management of $\mathrm{ICH}$, whereas the indications for neurosurgical treatment and post-operative ICH treatment are not outlined in detail, and are thus open for individual interpretation and potentially biased decision making [9].

Sweden has a tax-funded homogenous health care system, which ensures the population equal access to health care services. Furthermore, neurosurgical care is only provided by six centres in Sweden, allocated in different tertiary referral hospitals. They each serve a defined geographic area, and together, they are responsible for all neurosurgical care of the 10 million inhabitants.

We performed a nation-wide retrospective observational study of all neurosurgically treated patients with $\mathrm{ICH}$ in Sweden during a 5-year period (2011-2015). The main aim of this study was to systematically elucidate similarities and differences in treatment and indication for surgery among neurosurgical centres in Sweden, in ICH patients, for whom defined clinical guidelines are lacking.

\section{Method}

Data was collected by examining medical records and neuroimaging from all six neurosurgical centres in Sweden (Lund, Gothenburg, Linköping, Stockholm, Uppsala and Umeå) during the period 1 January 2011 to 31 December 2015. The study was approved by the regional board of ethical review in Uppsala, Sweden.

The neurosurgical centres are found in the following hospitals (from south to north) in Sweden with their respective population catchment size indicated in parenthesis: Lund (1.8 million), Gothenburg (1.8 million), Linköping (1.0 million), Stockholm (2.3 million), Uppsala (2.0 million) and Umeå (0.9 million).

Patients with a first-listed ICD-10 diagnosis code I61.0-9 admitted and treated during the 5-year period were evaluated for inclusion. Those included were adult patients with neurosurgically treated supratentorial intracerebral haemorrhage (ICH), while patients with infratentorial ICH (cerebellum and brainstem), and ICH related to trauma, neoplasm, vascular malformation, venous sinus thrombosis or a haemorrhagic transformation of ischemic stroke were excluded, as were patients not undergoing surgery.

Patients' age, gender and past medical history including hypertension, diabetes, previous myocardial infarction and 
previous stroke was documented. Treatment with antihypertensive-, antiplatelet-, warfarin and non-vitamin $\mathrm{K}$ oral anticoagulant drugs (NOACs) was recorded as well as information on neuroimaging with computed tomography scan (CT), CT angiography (CTA), magnetic resonance imaging (MRI) and digital subtraction angiography (DSA) performed during the acute treatment period. Based on the CT imaging, the hematoma was defined as either lobar or deep-seated. Lobar hematoma incorporated haemorrhages in the frontal, parietal, temporal and occipital lobes originating from the cortex and subcortical white matter [19, 31]. Deep-seated hematomas comprised haemorrhages originating from the basal ganglia and thalamus $[19,30,46]$. The presence of hydrocephalus (HC) [47] and intraventricular haemorrhage (IVH) was documented. The severity of IVH was graded using the LeRoux numerical scoring system [28]. The volume of the intracerebral hematoma was calculated using the $\mathrm{ABC} / 2$ technique [27, 49]. Glasgow coma scale motor response (GCS-M), pupillary size, asymmetry and reaction to light, arm and leg paresis/paralysis and dysphasia were documented preoperatively and at discharge, as was the length of stay (LOS) in the neurocritical care (NCC) unit. A possible transtentorial herniation was defined as a decreased level of consciousness in combination with signs indicating compression of the third cranial nerve such as uni- or bilateral pupil dilatation with or without sluggish or unresponsive reaction to light.

The type of surgical procedure, craniotomy and ICH evacuation, treatment with EVD alone, or other surgical technique was documented and the number of reoperations was noted. The use of ICP monitoring and the number of days with ICP monitoring were recorded, as was the use and duration of any drainage of cerebrospinal fluid (CSF) and mechanical ventilator. Primary end-point was 30-day mortality.

The total incidence of supratentorial intracerebral haemorrhage in our country was retrieved from the National Stroke Register, which has a 90\% national coverage [36].

Statistical analysis was done with SPSS Statistics 22. Continuous variables were presented as mean (SD) or median (IQR 25th-75th percentile) values. Categorical variables were presented as numbers and percentages.
Chi-square test was used for comparison of proportions of categorical variables. Adjusted residuals were investigated to localise effect as sample sizes were uneven among groups, and $> \pm 1.96$ (2SD) was considered indicative of effect location. Continuous variables were analysed with ANOVA, and multiple comparisons using Games-Howell were used for post hoc analysis. Missing values were excluded from analysis. Patients lost to follow-up $(N=4)$ were excluded from analysis. All tests were two-tailed. A $p$ value of $<.05$ was considered statistically significant.

\section{Results}

Between 1 January 2011 and 31 December 2015, 578 patients (mean age $59 \pm 12$ years) were treated surgically for supratentorial ICH in Sweden. Of these, 39\% were female and $61 \%$ were male, with 402 patients treated with craniotomy and ICH evacuation, whereas 176 were treated with EVD alone. The incidence of neurosurgical intervention was $1.37 / 100,000$ inhabitants for all included patients, $0.8 / 100,000$ for those treated with craniotomy and ICH evacuation and $0.4 / 100,000$ for those treated by EVD only (Table 1). The incidence of supratentorial ICH (approximately $80 \%$ of all $\mathrm{ICH}$ ) in Sweden in the study time period was approximately 2370 patients per year [36]. Thus, approximately $5 \%$ of all patients with supratentorial $\mathrm{ICH}$ in the country were treated surgically during the study period, with similar incidence of neurosurgical intervention among the different centres (Table 1).

The average patient age did not differ significantly between centres $\left(\chi^{2}(20,577)=27.4, p=.125\right.$; Fig. $1 \mathrm{a}$; grouped by $<50$ years, then each decade until 80 years), nor did the preoperative GCS-M score grouped into 1-2, $3-$ 4 and 5-6, respectively $\left(\chi^{2}(10,545)=13.13, p=.22\right.$; Table 2$)$. Patient age did not differ between centres when analysed also as a continuous variable $(F(5)=1.6, p=.16)$. The proportion of patients with signs of possible transtentorial herniation was significantly higher at one centre (Umeå) compared to the others $\left(\chi^{2}(5)=14.5, p=.01\right.$; Table 2$)$. There was a difference among centres in the proportion of females in the entire cohort
Table 1 Incidence of surgical intervention for intracerebral haemorrhage per 100,000 inhabitants, presented for each centre

\begin{tabular}{llllllll}
\hline Incidence per 100,000 inhabitants & & & & & & \\
\hline & Lund & Gothenburg & Linköping & Stockholm & Uppsala & Umeå & All \\
\hline Entire patient cohort & 1.26 & 0.75 & 1.53 & 1.03 & 1.22 & 1.72 & 1.17 \\
Craniotomy & 1.03 & 0.47 & 1.07 & 0.65 & 0.79 & 1.31 & 0.82 \\
EVD alone & 0.22 & 0.28 & 0.47 & 0.38 & 0.43 & 0.41 & 0.36 \\
\hline
\end{tabular}

EVD external ventricular drainage 
a

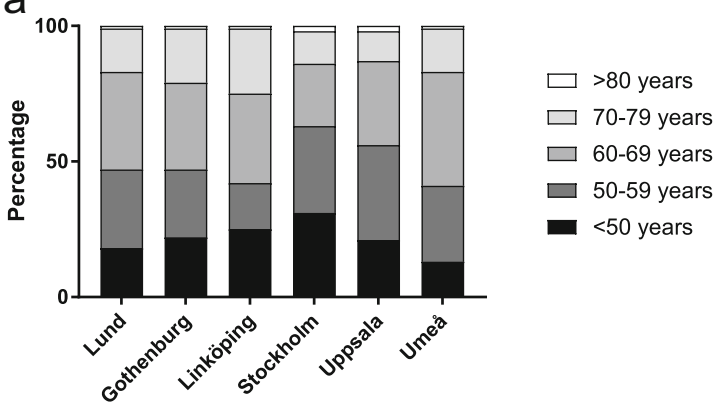

C

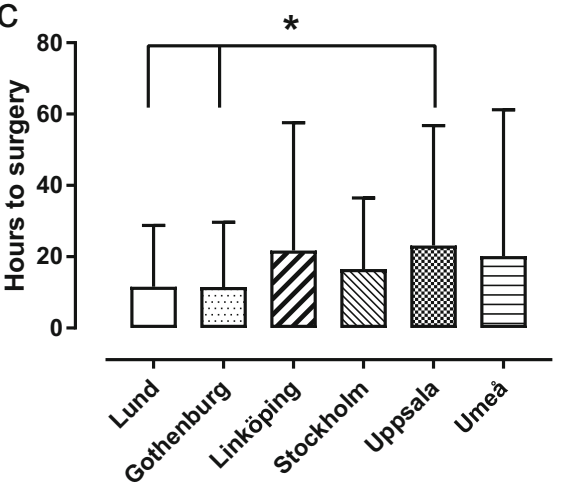

Fig. 1 a Age distribution of patients at the centres showing percentage of all patients in each category divided by decade from 50 to 80 . There was no significant difference in the age of the patients treated surgically $\left(\chi^{2}(20,577)=27.38, p=.13\right)$. b Variations in hematoma volume of

$\left(\chi^{2}(5)=13.5, p=.019 ;\right.$ Table 2). The proportion of left-sided ICH in the entire patient cohort differed among centres $\left(\chi^{2}(5)=13.8, p=.017\right.$; Table 2).

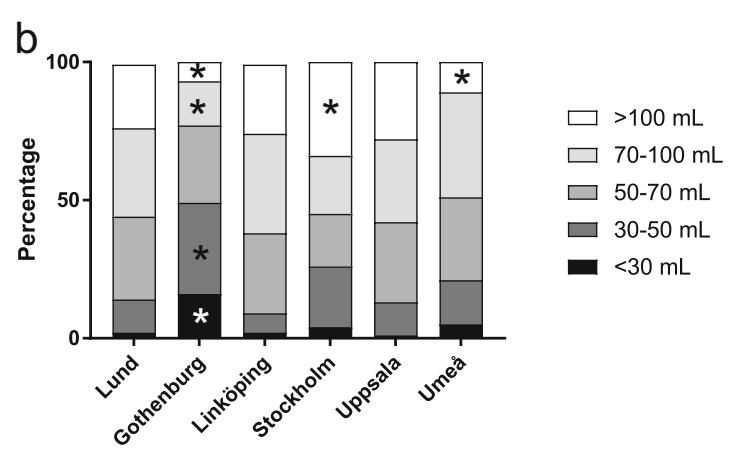

patients treated by craniotomy and ICH evacuation among the different centres. *Significantly different proportion compared to other centres $\left(\chi^{2}(5)=52.79, p<.001\right)$. $\mathbf{c}$ Difference in time to surgery (hours) from ICH onset. *A significant difference between the centres $(F(5)=2.8, p=.02)$

The average hematoma volume was significantly smaller at one centre (Gothenburg) compared to all others $\left(\chi^{2}(5)=52.8\right.$, $p<.001$; Fig. $1 \mathrm{~b}$; grouped as $<30 \mathrm{~mL} ; 30-50 \mathrm{~mL} ; 50-70 \mathrm{~mL}$;

Table 2 Patient characteristics. $N(\%)$

Patient characteristics entire cohort, $N(\%)$

\begin{tabular}{|c|c|c|c|c|c|c|c|}
\hline & Lund $N=112$ & Gothenburg $N=69$ & Linköping $N=79$ & Stockholm $N=118$ & Uppsala $N=124$ & Umeå $N=76$ & $p$ value \\
\hline Female & $40(36)$ & $36(52) *$ & $36(46)$ & $44(37)$ & $50(40)$ & $19(25) \neq$ & .019 \\
\hline \multicolumn{7}{|c|}{ GCS-M on admission } & .217 \\
\hline $1-2$ & $4(4)$ & $4(6)$ & $9(12)$ & $7(7)$ & $4(3)$ & $5(7)$ & \\
\hline $3-4$ & $17(15)$ & $18(26)$ & $15(20)$ & $16(17)$ & $19(16)$ & $11(15)$ & \\
\hline $5-6$ & $90(81)$ & $47(68)$ & $52(68)$ & $71(76)$ & $99(81)$ & $57(78)$ & \\
\hline Abn. Pupil(s) & $28(25)$ & $7(10) \neq$ & $16(20)$ & $20(17)$ & $16(13)$ & $22(29) *$ & .013 \\
\hline Left hemisphere & $47(42)$ & $26(38)$ & $43(54)$ & $51(43)$ & $74(60) *$ & $35(46)$ & .017 \\
\hline $\mathrm{HC}$ & $33(30) \neq$ & $24(35)$ & $37(47)$ & $68(58) *$ & $74(60) *$ & $16(21) \neq$ & $<.001$ \\
\hline IVH & $61(61)$ & $45(65)$ & $60(77)$ & $81(69)$ & $91(75)$ & $57(75)$ & .113 \\
\hline Craniotomy & $92(82) \neq$ & $43(62)$ & $55(70)$ & $74(63)$ & $80(65)$ & $58(76)$ & .007 \\
\hline Deep-seated & $60(54)$ & $41(59)$ & $60(76) *$ & $49(42) \neq$ & $84(68) *$ & $47(62)$ & $<.001$ \\
\hline
\end{tabular}

* Significantly higher than other centres

$\ddagger$ Significantly lower than other centres. $P<.05$ is indicated by italics

$N$ number of patients, GCS-M Glasgow Coma Score Motor component, Abn. Pupil(s) one or two dilated pupils with abnormal reaction to light, $H C$ hydrocephalus, $I V H$ intraventricular haemorrhage 
Table 3 Frequency of comorbidities of entire patient cohort. $N(\%)$

\begin{tabular}{llllllll}
\hline Comorbidities, $N(\%)$ & & & & & \\
\hline & Lund & Gothenburg & Linköping & Stockholm & Uppsala & Umeå & $p$ value \\
\hline VKA & $12(11)$ & $4(6)$ & $12(15)$ & $6(5)$ & $15(12)$ & $10(13)$ & .160 \\
NOAC & $1(1)$ & $0(0)$ & $0(0)$ & $1(1)$ & $4(3)$ & $0(0)$ & - \\
Antiplatelet & $17(15)$ & $14(20)$ & $16(20)$ & $17(15)$ & $22(18)$ & $13(17)$ & .876 \\
Thrombolytic & $2(2)$ & $0(0)$ & $3(4)$ & $0(0)$ & $1(1)$ & $0(0)$ & - \\
DM Type I & $1(1)$ & $5(7)$ & $2(3)$ & $1(1)$ & $3(2)$ & $1(1)$ & .071 \\
DM Type II & $13(12)$ & $9(13)$ & $11(14)$ & $15(13)$ & $12(10)$ & $9(12)$ & .956 \\
HT (med) & $44(39)$ & $36(52)$ & $35(44)$ & $52(44)$ & $70(57)$ & $41(54)$ & .085 \\
HT (no med.) & $41(37)$ & $32(46)$ & $25(32)$ & $40(34)$ & $51(41)$ & $34(45)$ & .300 \\
Previous MI & $8(7)$ & $8(12)$ & $7(9)$ & $8(7)$ & $7(6)$ & $6(8)$ & .769 \\
Previous CVL & $11(10)$ & $7(10)$ & $7(9)$ & $11(9)$ & $29(23) *$ & $6(8)$ & .003 \\
\hline
\end{tabular}

*Significantly higher than other centres

$P<.05$ is indicated by italics

$V K A$ vitamin-K antagonist, $N O A C$ non vitamin-K oral anticoagulant, $D M$ diabetes mellitus, $H T$ hypertension, med medicated, no med not on medication, $M I$ myocardial infarction, $C V L$ cerebrovascular lesion
70-100 mL; > $100 \mathrm{~mL}$ ). This difference remained statistically significant also when volume was analysed as a continuous variable $(F(5)=5.8, p<.001)$. Time to surgery varied between centres $(F(5)=2.8, p=.02$; Fig. 1c).

The prevalence of co-morbidities, including previously known hypertension, acute untreated hypertension, diabetes, previous myocardial infarction, antihypertensive drugs, antiplatelet drugs, warfarin and non-vitamin $\mathrm{K}$ anticoagulant (NOAC) drugs, was similar across centres, although one centre had a higher frequency of patients with prior stroke $\left(\chi^{2}(5)=18.2, p=.003\right.$; Table 3$)$.

In the entire cohort, the choice between craniotomy and ICH evacuation versus treatment with EVD alone differed significantly among centres $\left(\chi^{2}(5)=15.8, p=.007\right.$; Table 2$)$. The frequency of craniotomy and $\mathrm{ICH}$ evacuation was similar for lobar haemorrhages (91-100\%), although differed significantly $(p<.001)$ for deep-seated haemorrhages, ranging from 22 to
$68 \%$ treated by craniotomy and ICH evacuation (Table 4), while the remaining were treated by EVD only.

In addition, the proportion of deep-seated hematomas compared to lobar hematomas undergoing any surgical treatment differed between centres with two centres (Linköping and Uppsala) operating significantly more deep-seated ICH and another centre (Stockholm) significantly more lobar ICH $\left(\chi^{2}(5)=29.8, p<.001\right.$; Table 4$)$. There was a small number of patients $(n=9,1.6 \%)$ in the entire patient cohort undergoing surgery classed as "other" which included endoscopic surgery. The frequency of reoperations was $8 \%$ in the entire cohort, and this did not differ significantly between centres $\left(\chi^{2}(5)=10.2, p=.07\right)$.

In the group of patients treated by craniotomy and $\mathrm{ICH}$ evacuation, there was no difference between centres in the number of patients with intraventricular haemorrhage $\left(\chi^{2}(5)=8.9, p=.064\right)$, whereas the frequency of

Table 4 Surgical method in deep-seated vs lobar ICH. N(\%)

Proportion undergoing craniotomy, $N(\%)$

\begin{tabular}{llllllll}
\hline & Lund $N=112$ & Gothenburg $N=69$ & Linköping $N=79$ & Stockholm $N=118$ & Uppsala $N=124$ & Umeå $N=76$ & $p$ value \\
Entire patient cohort & $92(82)^{*}$ & $43(62)$ & $55(70)$ & $74(63)$ & $80(65)$ & $58(76)$ & .007 \\
& Lund $N=60$ & Gothenburg $N=41$ & Linköping $N=60$ & Stockholm $N=49$ & Uppsala $N=84$ & Umeå $N=47$ & $p$ value \\
Deep-seated ICH & $41(68)^{*}$ & $15(37) \neq$ & $36(60)$ & $11(22) \neq$ & $42(50)$ & $30(64)$ & $<.001$ \\
& Lund $N=52$ & Gothenburg $N=28$ & Linköping $N=19$ & Stockholm $N=69$ & Uppsala $N=40$ & Umeå $N=29$ & $p$ value \\
Lobar ICH & $51(98)$ & $28(100)$ & $19(100)$ & $63(91)$ & $38(95)$ & $28(97)$ & .281 \\
\hline
\end{tabular}

*Significantly higher than other centres

$\ddagger$ Significantly lower than other centres. $P<.05$ is indicated by italics

$N$ number of patients, $I C H$ intracerebral haemorrhage 
Table 5 ICH characteristics divided by treatment choice. $N(\%)$

ICH characteristics, $N(\%)$

Patients treated with craniotomy with ICH evacuation

\begin{tabular}{|c|c|c|c|c|c|c|c|}
\hline & Lund $N=90$ & Gothenburg $N=43$ & Linköping $N=55$ & Stockholm $N=74$ & Uppsala $N=80$ & Umeå $N=58$ & $p$ value \\
\hline IVH & $43(52)$ & $19(44)$ & $37(69)$ & $39(53)$ & $50(63)$ & $39(67)$ & .064 \\
\hline $\mathrm{HC}$ & $16(17) \neq$ & $1(2) \neq$ & $15(27)$ & $30(41) *$ & $36(45) *$ & $5(9) \neq$ & $<.001$ \\
\hline Left hemisphere & $39(42)$ & $15(35)$ & $28(51)$ & $28(38)$ & $44(55)$ & $28(48)$ & .167 \\
\hline Deep-seated & $41(45)$ & $15(35)$ & $36(66) *$ & $11(15) \dagger$ & $42(53)$ & $30(52)$ & $<.001$ \\
\hline Female & $35(38)$ & $21(49)$ & $22(40)$ & $27(37)$ & $29(36)$ & $12(21)$ & .091 \\
\hline \multicolumn{8}{|c|}{ Patients treated with EVD alone } \\
\hline & Lund $N=20$ & Gothenburg $N=26$ & Linköping $N=24$ & Stockholm $N=44$ & Uppsala $N=44$ & Umeå $N=18$ & $p$ value \\
\hline IVH & $18(100)$ & $26(100)$ & $23(96)$ & $42(96)$ & $41(98)$ & $18(100)$ & .732 \\
\hline $\mathrm{HC}$ & $17(85)$ & $23(89)$ & $22(92)$ & $38(86)$ & $38(86)$ & $11(61)$ & .106 \\
\hline Left hemisphere & $6(30)$ & $11(42)$ & $7(29)$ & $23(52)$ & $24(55)$ & $7(39)$ & .210 \\
\hline Deep-seated & $19(95)$ & $26(100)$ & $24(100)$ & $38(86)$ & $42(96)$ & $17(94)$ & .139 \\
\hline Female & $5(25)$ & $15(58)$ & $14(58)$ & $17(39)$ & $21(48)$ & $7(39)$ & .169 \\
\hline
\end{tabular}

*Significantly higher than other centres

$¥$ Significantly lower than other centres. $P<.05$ is indicated by italics

$N$ number of patients, $I C H$ intracerebral haemorrhage, $I V H$ intraventricular haemorrhage, $H C$ hydrocephalus, $E V D$ external ventricular drain

hydrocephalus differed among centres $\left(\chi^{2}(5)=48.8, p<.001\right.$; Table 5), as it did also for the entire patient cohort $\left(\chi^{2}(5)=\right.$ 49.8, $p<.001$; Table 2).

All centres performed a preoperative computed tomography (CT). The use of CT-angiography varied between 39.1 and $76.3 \%$ between centres $\left(\chi^{2}(5)=40.0, p<.001\right.$; Table 6). Additional neuroimaging was performed in several centres including magnetic resonance imaging, contrast-enhanced CT and digital subtraction angiography (Table 6).
Post-operative management showed some variability among centres. In patients treated with craniotomy, two centres used less ICP monitoring than the others $\left(\chi^{2}(5)=112.1\right.$, $p<.001$; Table 7$)$ and the duration of ICP monitoring differed $(F(5)=4.0, p=.002$; Fig. $2 \mathrm{a})$, as did the duration of CSF drainage $(F(5)=3.1, p=.01$; Fig. 2b). The use of mechanical ventilation also varied significantly in frequency $\left(\chi^{2}(5)=\right.$ 21.1, $p=.001$; Table 7$)$ and duration $(F(5)=8.3, p<.001$; Fig. 2c). For patients treated with EVD alone, the use of ICP-monitoring $\left(\chi^{2}(5)=63.6, p<.001\right)$ and CSF drainage
Table 6 Neuroimaging used during the treatment period. $N(\%)$

\begin{tabular}{llllllll}
\hline \multicolumn{1}{l}{ Neuroimaging, $N(\%)$} & \multicolumn{1}{l}{} \\
\hline & Lund & Gothenburg & Linköping & Stockholm & Uppsala & Umeå & $p$ value \\
\hline CT & $109(97)$ & $69(100)$ & $79(100)$ & $117(99)$ & $121(98)$ & $76(100)$ & .27 \\
CTA & $57(51)$ & $27(39)$ & $46(58)$ & $90(76)^{*}$ & $53(43)$ & $49(65)$ & .000 \\
Other§ & $9(8)$ & $2(3)$ & $10(13)$ & $15(13)^{*}$ & $4(3)$ & $2(3)$ & .007 \\
§ Other imaging techniques¥: & & & & & \\
CECT & $6(5)$ & $2(3)$ & $2(3)$ & $5(4)$ & $1(1)$ & $0(0)$ & - \\
MRI & $2(2)$ & $0(0)$ & $7(9)$ & $9(8)$ & $2(2)$ & $2(3)$ & - \\
MRA & $0(0)$ & $0(0)$ & $0(0)$ & $0(0)$ & $1(1)$ & $0(0)$ & - \\
$D S A$ & $2(2)$ & $0(0)$ & $1(1)$ & $4(3)$ & $1(1)$ & $0(0)$ & - \\
\hline
\end{tabular}

*Significantly higher than other centres

$\ddagger$ Significantly lower than other centres. $P<.05$ is indicated by italics. $\S$ indicates other neuroimaging. ¥-numbers too small for statistical analysis

$N$ number of patients, $C T$ computer tomography, CTA computer tomography angiography, Other all other neuroimaging, including: CECT contrast-enhanced computer tomography, MRI magnetic resonance imaging, MRA magnetic resonance imaging angiography, DSA digital subtraction angiography 
Table 7 Neurocritical care parameters. $N(\%)$

Neurocritical care strategies, $N(\%)$

Patients treated by craniotomy and ICH evacuation

\begin{tabular}{|c|c|c|c|c|c|c|c|}
\hline & Lund $N=90$ & Gothenburg $N=43$ & Linköping $N=55$ & Stockholm $N=74$ & Uppsala $N=80$ & Umeå $N=58$ & $p$ value \\
\hline ICP-monitoring & $26(28) \neq$ & $12(28) \neq$ & $45(82) *$ & $40(54)$ & $67(84) *$ & $53(91) *$ & $<.001$ \\
\hline CSF-drainage & $15(16) \neq$ & $2(5)+$ & $12(22)$ & $29(39) *$ & $31(39) *$ & $20(35)$ & $<.001$ \\
\hline Mechanical ventilation & $60(66) \neq$ & $31(72)$ & $48(87)$ & $56(77)$ & $67(84)$ & $54(93) *$ & .001 \\
\hline \multicolumn{8}{|c|}{ Patients treated by EVD alone } \\
\hline & Lund $N=20$ & Gothenburg $N=26$ & Linköping $N=24$ & Stockholm $N=44$ & Uppsala $N=44$ & Umeå $N=18$ & $p$ value \\
\hline ICP-monitoring & $17(85)$ & $11(42) \neq$ & $23(96)$ & $43(98) *$ & $43(98) *$ & $18(100)$ & $<.001$ \\
\hline CSF-drainage & $16(80)$ & $24(92)$ & $20(83)$ & $43(98) *$ & $24(55) \neq$ & $18(100) *$ & $<.001$ \\
\hline Mechanical ventilation & $12(60)$ & $22(85)$ & $19(79)$ & $36(82)$ & $37(84)$ & $17(94)$ & .131 \\
\hline
\end{tabular}

*Significantly higher than other centres

tSignificantly lower than other centres. $P<.05$ is indicated by italics

$N$ number of patients, $I C H$ intracerebral haemorrhage, $I C P$ intracranial pressure, $C S F$ cerebrospinal fluid, $E V D$ external ventricular drain

$\left(\chi^{2}(5)=36.3, p<.001\right)$ differed among centres (Table 7$)$ as did the duration of ICP-monitoring $(F(5)=6.6, p<.001)$, CSF-drainage $(F(5)=7.9, p<.001)$ and mechanical ventilation $(F(5)=4.0, p=.002$; Fig. $2 \mathrm{~d}-\mathrm{f})$.
One centre (Stockholm) was unable to provide detailed data on length of stay (LOS) in a NCC unit. The mean LOS in the NCC unit of the remaining centres was $7.7( \pm 6)$ days, with significant differences among centres (data not shown; a

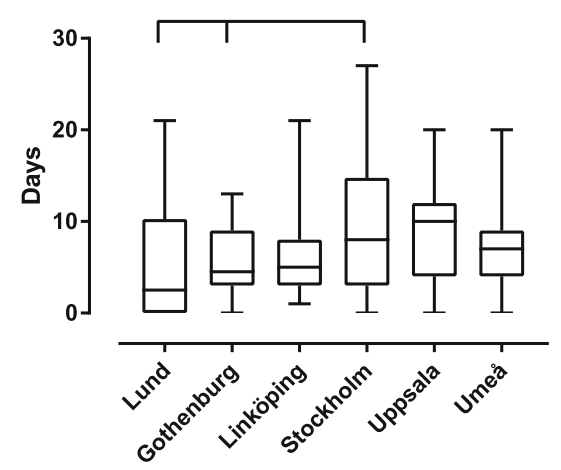

d

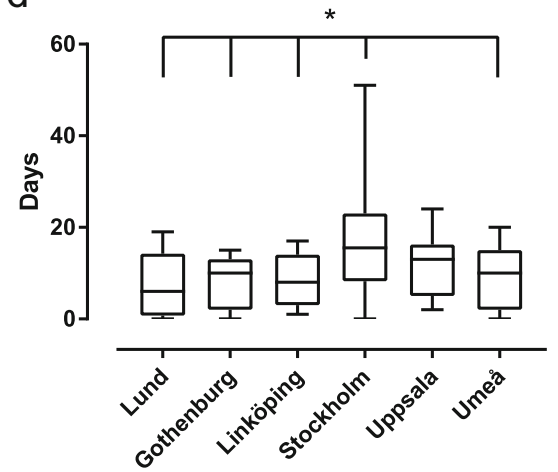

b

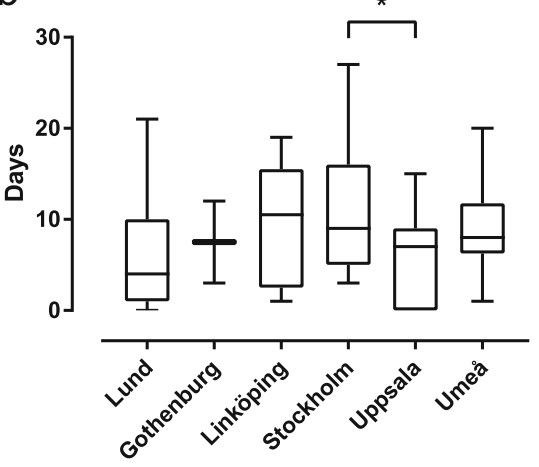

e

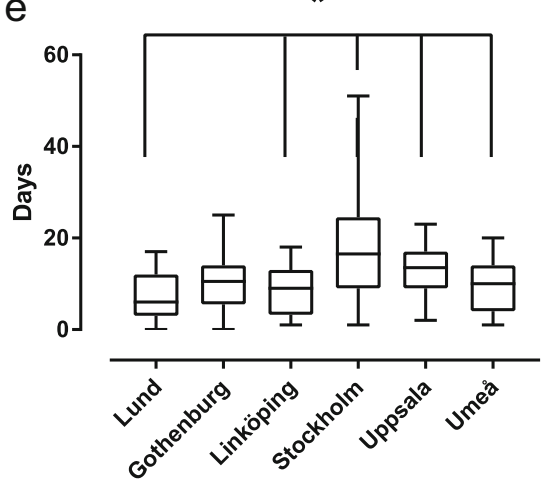

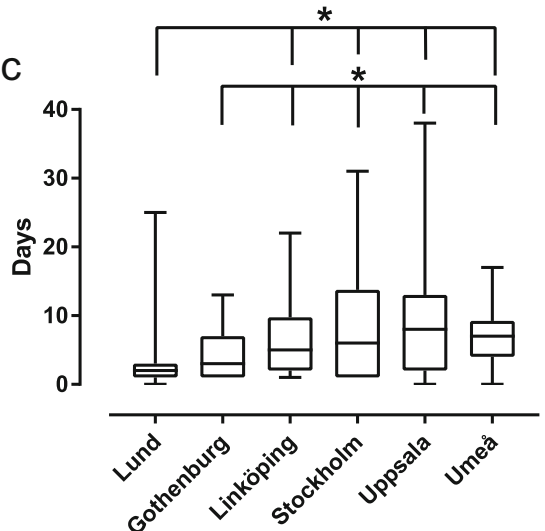

$f$

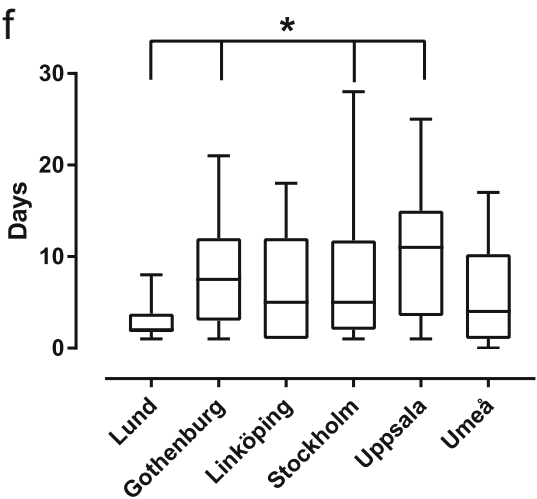

Fig. 2 For patients treated with craniotomy with ICH evacuation, the duration of use of a ICP-monitoring, $\mathbf{b}$ CSF-drainage and $\mathbf{c}$ mechanical ventilation differed significantly between centres as it did for patients treated by EVD alone where ICP-monitoring, CSF-drainage and mechanical ventilation are shown in $\mathbf{d}$, e and $\mathbf{f}$, respectively. Abbreviations: $\mathrm{ICH}=$ intracerebral haemorrhage; $\mathrm{EVD}=$ external ventricular drainage; $\mathrm{ICP}=$ intracranial pressure; $\mathrm{CSF}=$ cerebrospinal fluid. $* p<.05$ 
Table 8 30-day mortality. $N(\%)$

\begin{tabular}{llllllll}
\hline 30-day mortality, $N(\%)$ & \multicolumn{1}{l}{} \\
\hline & Lund & Gothenburg & Linköping & Stockholm & Uppsala & Umeå & $p$ value \\
\hline Entire patient cohort & $11(10) \neq$ & $10(15)$ & $20(25)^{*}$ & $13(11)$ & $21(17)$ & $21(28) *$ & .004 \\
Craniotomy & $9(10)$ & $4(9)$ & $13(24)^{*}$ & $5(7)$ & $12(15)$ & $13(22)^{*}$ & .026 \\
EVD & $2(10)$ & $6(23)$ & $7(29)$ & $8(19)$ & $9(21)$ & $8(44)$ & .170 \\
\hline
\end{tabular}

*Significantly higher than other centres

† Significantly lower than other centres. $P<.05$ is indicated by italics

$N$ number of patients, $E V D$ external ventricular drain

$F(4)=7.4, p<.001)$. The organisation of neurocritical care differed between centres with five having dedicated neurocritical care units (Lund, Gothenburg, Linköping, Stockholm and Uppsala), whereas one (Umeå) treated neurocritical care patients within the general ICU setting.

The 30-day mortality was similar between centres for patients treated by EVD alone but showed a small but significant difference for patients treated by craniotomy and ICH evacuation $\left(\chi^{2}(5)=17.1, p=.026\right.$; Table 8$)$ and for the entire patient cohort ( $p=.004$; Table 8 ). The 30-day mortality for the entire cohort grouped by preoperative GCS-M score was $50 \%$ ( $n=$ $4 / 8)$ for GCS-M 1, 42\% $(n=10 / 24)$ for GCS-M 2, $21 \%(n=6 /$ 28) for GCS-M 3, $25 \%(n=17 / 68)$ for GCS-M 4, $16 \%(n=$ 35/215) for GCS-M 5 and 10\% $(n=20 / 198)$ for GCS-M 6. Overall 30-day mortality was $17 \%(n=96 / 574)$.

\section{Discussion}

This is the first study evaluating nation-wide differences in surgical management of intracerebral haemorrhage (ICH). We compared the surgical indications, treatment and postoperative management of patients with supratentorial $\mathrm{ICH}$ among the neurosurgical centres in Sweden during a 5-year period. In previous studies evaluating trends in surgical management of $\mathrm{ICH}$, either in samples of the population or in single centres, a large variability in treatment strategies has been found [1, 5, 25]. A subgroup analysis of the STICHtrial data suggested large international variations in surgical practice and treatment of ICH [13], highlighting the need for studies of large cohorts of ICH patients to characterise the variability of management and its impact on outcome. A recent retrospective single-centre study showed favourable outcome following surgery for ICH, similar for both deep-seated and lobar location, thus adding to the ongoing debate on the indications for surgical intervention in ICH [19].

Our study shows that the frequency of surgical treatment of patients with supratentorial ICH in Sweden was 5\%, which is in line with previous studies $[1,13,25,38]$. The number of patients treated at the different neurosurgical centres was similar when adjusted for the size of their respective catchment populations. The majority of patients were treated with craniotomy and ICH evacuation. Patient's age and medical history, preoperative neurological status, presence of intraventricular blood and/or hydrocephalus were comparable among the six centres indicating, to some degree, similar criteria for neurosurgical intervention in our country. In addition, the number of reoperations was similar. However, ICH volume, the proportion of deep-seated haemorrhages, use of ICP-monitoring, CSF drainage, post-operative mechanical ventilation and length of stay in neurocritical care unit showed variability between centres. Importantly, although mortality rates were slightly higher in some centres, we cannot conclude that the observed management differences influenced mortality.

The subgroup analysis of the STICH trial suggested a tentative benefit of early surgery over conservative treatment for patients with an $\mathrm{ICH}<1 \mathrm{~cm}$ from the cortical surface [30], i.e. a lobar location of ICH. These observations led to protocol used in the subsequent STICH II trial. In our present study, the difference in mortality rates for patients treated by craniotomy might reflect the variation in the proportion of deep-seated ICH evacuated by craniotomy. The 30-day mortality in our large ICH cohort was nevertheless comparable to, or lower than, mortality reported in previous studies of surgically treated ICH patients [1, 5, 13, 30, 38]. Furthermore, 30-day mortality rates in this study are lower than those predicted for the entire ICH patient population [17, 40], possibly suggesting a benefit of surgical treatment. European Guidelines for ICH treatment state that patients presenting with GCS 9-12 may have the best clinical benefit of surgery [42]. In the present cohort, the 30-day mortality for the poor-grade patients (GCS-M 1-3) was as low as $21-50 \%$, arguing for a lifesaving role of ICH surgery in combination with neurocritical care. This can be contrasted to the STICH cohort where a uniformly bad outcome was reported in comatose patients [30].

In the present study, only $1.6 \%$ of patients were treated with surgical methods other than craniotomy and $\mathrm{ICH}$ evacuation or EVD treatment alone, including endoscopic surgery. Our data show that minimally invasive surgery (MIS) was not often used in Sweden in 2011-2015; however, with accumulating research data on MIS becoming gradually available, this might change in the future, provided that a clinical benefit of MIS is shown. 
Time to surgery differed significantly between centres, likely reflecting shorter distances from referral hospitals to the neurosurgical centres in some areas of our country. This may explain why the northernmost neurosurgical department (Umeå), covering a large geographic area [43], had significantly more patients showing signs of possible transtentorial herniation prior to surgery.

Neurocritical care is organised differently at the various centres where some use dedicated neurocritical care units whereas others use a general ICU. This could contribute to the differences in neurocritical care management noted in this study, including the use of ICP monitoring, and early extubation.

Limitations of the present study include the lack of longterm follow-up, detailed functional outcome and quality-oflife data as well as the retrospective study design. The majority of ICH studies report outcome up to 3 or 6 months post ICH onset and only a few studies report on long-term outcome after ICH $[12,26]$. Determining a long-term prognosis for functional outcome in the acute phase is difficult for ICH patients, further complicated by a shortage of long-term outcome studies [23], thus a long-term follow-up of the present cohort is warranted.

Another limitation of the study is the lack of details on medical management, such as specific systolic blood pressure levels or choice of antihypertensive medication, which might have added valuable information. Presumably, all centres aim for blood pressure control in accordance with current guideline recommendations, thus limiting variability in these parameters, although our pragmatic study design does not allow us to confirm this.

A strength of this present study is the comprehensive, nation-wide inclusion of each patient subjected to surgical treatment for ICH, which, to our knowledge, has not been done previously. The multi-centre design of this study enabled the detection of both differences and similarities in ICH management, highlighting the need for refined guidelines. In many aspects, the criteria for neurosurgical intervention in Sweden were homogenous across centres. This could, in part, be explained by a uniform resident training through the Nordic (www.neurosurgery.no), and the European Association of Neurosurgical Societies (EANS) training courses, attended by the majority of neurosurgical residents in Sweden. However, in view of the lack of detailed management protocols, local treatment policies may develop into different treatment and management strategies which could markedly influence patient outcome $[16,20,22,23]$.

\section{Conclusion}

Our study, the first nation-wide study of neurosurgically treated ICH patients, shows that a congruent health care organisation and a rather homogeneous training of neurosurgeons can result in similarities in selection criteria for neurosurgical intervention. Nevertheless, there were still important differences in patient selection, choice of surgical method, and post-operative management among neurosurgical centres, plausibly reflecting regional practices and more importantly a lack of defined guidelines for many aspects of ICH care. Our results identify areas where additional studies are needed to provide better evidence for ICH management. Future studies should aim to determine guidelines for postoperative care of surgically treated ICH patients and should also characterise the long-term functional outcome and quality of life in large cohorts of surgically treated ICH-patients.

Additional information All data can be made available upon request.

Authors' contribution AF, LT, and NM contributed equally to the writing of the manuscript. HNR, AH, ET, LT, AB, HZ, ME, and SM assembled data. Statistical analysis was done by LT. Idea and project planning was performed by AF, LT and NM. All authors read, edited and approved the manuscript.

Funding Local Hospital and ALF funding, and the Swedish Stroke Association provided financial support, however, had no role in the design, conduct or reporting of the research.

\section{Compliance with ethical standards}

Conflict of interest All authors certify that they have no affiliations with or involvement in any organisation or entity with any financial interest (such as honoraria; educational grants; participation in speakers' bureaus; membership, employment, consultancies, stock ownership, or other equity interest; and expert testimony or patent-licencing arrangements), or non-financial interest (such as personal or professional relationships, affiliations, knowledge or beliefs) in the subject matter or materials discussed in this manuscript.

Ethical approval All procedures performed in studies involving human participants were in accordance with the ethical standards of the institutional and/or national research committee and with the 1964 Helsinki declaration and its later amendments or comparable ethical standards. For this type of study, formal consent is not required.

Open Access This article is distributed under the terms of the Creative Commons Attribution 4.0 International License (http:// creativecommons.org/licenses/by/4.0/), which permits unrestricted use, distribution, and reproduction in any medium, provided you give appropriate credit to the original author(s) and the source, provide a link to the Creative Commons license, and indicate if changes were made.

\section{References}

1. Adeoye O, Ringer A, Hornung R, Khatri P, Zuccarello M, Kleindorfer D (2010) Trends in surgical management and mortality of intracerebral hemorrhage in the United States before and after the STICH trial. Neurocrit Care 13:82-86

2. Akhigbe T, Zolnourian A (2017) Role of surgery in the management of patients with supratentorial spontaneous intracerebral hematoma: critical appraisal of evidence. J Clin Neurosci 39:35-38

3. Al-Mufti F, Thabet AM, Singh T, El-Ghanem M, Amuluru K, Gandhi CD (2018) Clinical and radiographic predictors of intracerebral hemorrhage outcome. Interv Neurol 7:118-136 
4. An SJ, Kim TJ, Yoon BW (2017) Epidemiology, risk factors, and clinical features of intracerebral hemorrhage: an update. Journal of stroke 19:3-10

5. Andaluz N, Zuccarello M (2009) Recent trends in the treatment of spontaneous intracerebral hemorrhage: analysis of a nationwide inpatient database. J Neurosurg 110:403-410

6. Auer LM, Deinsberger W, Niederkorn K, Gell G, Kleinert R, Schneider G, Holzer P, Bone G, Mokry M, Korner E et al (1989) Endoscopic surgery versus medical treatment for spontaneous intracerebral hematoma: a randomized study. J Neurosurg 70:530-535

7. Batjer HH, Reisch JS, Allen BC, Plaizier LJ, Su CJ (1990) Failure of surgery to improve outcome in hypertensive putaminal hemorrhage. A prospective randomized trial. Arch Neurol 47:1103-1106

8. Cordonnier C, Demchuk A, Ziai W, Anderson CS (2018) Intracerebral haemorrhage: current approaches to acute management. Lancet 392:1257-1268

9. Creutzfeldt CJ, Holloway RG (2012) Treatment decisions after severe stroke: uncertainty and biases. Stroke 43:3405-3408

10. Feigin VL, Lawes CM, Bennett DA, Barker-Collo SL, Parag V (2009) Worldwide stroke incidence and early case fatality reported in 56 population-based studies: a systematic review. Lancet Neurol 8:355-369

11. Fiorella D, Zuckerman SL, Khan IS, Ganesh NK, Mocco J (2015) Intracerebral hemorrhage: a common and devastating disease in need of better treatment. World Neurosurg 84:1136-1141

12. Flaherty ML, Haverbusch M, Sekar P, Kissela B, Kleindorfer D, Moomaw CJ, Sauerbeck L, Schneider A, Broderick JP, Woo D (2006) Long-term mortality after intracerebral hemorrhage. Neurology 66:1182-1186

13. Gregson BA, Mendelow AD (2003) International variations in surgical practice for spontaneous intracerebral hemorrhage. Stroke 34: 2593-2597

14. Gregson BA, Broderick JP, Auer LM, Batjer H, Chen XC, Juvela S, Morgenstern LB, Pantazis GC, Teernstra OP, Wang WZ, Zuccarello M, Mendelow AD (2012) Individual patient data subgroup metaanalysis of surgery for spontaneous supratentorial intracerebral hemorrhage. Stroke 43:1496-1504

15. Hattori N, Katayama Y, Maya Y, Gatherer A (2004) Impact of stereotactic hematoma evacuation on activities of daily living during the chronic period following spontaneous putaminal hemorrhage: a randomized study. J Neurosurg 101:417-420

16. Hemphill JC 3rd, White DB (2009) Clinical nihilism in neuroemergencies. Emerg Med Clin N Am 27:27-37 vii-viii

17. Hemphill JC 3rd, Bonovich DC, Besmertis L, Manley GT, Johnston SC (2001) The ICH score: a simple, reliable grading scale for intracerebral hemorrhage. Stroke 32:891-897

18. Hemphill JC 3rd, Greenberg SM, Anderson CS, Becker K, Bendok BR, Cushman M, Fung GL, Goldstein JN, Macdonald RL, Mitchell PH, Scott PA, Selim MH, Woo D, American Heart Association Stroke C, Council on C, Stroke N, Council on Clinical C (2015) Guidelines for the Management of Spontaneous Intracerebral Hemorrhage: a guideline for healthcare professionals from the American Heart Association/American Stroke Association. Stroke 46:2032-2060

19. Hessington A, Tsitsopoulos PP, Fahlstrom A, Marklund N (2018) Favorable clinical outcome following surgical evacuation of deepseated and lobar supratentorial intracerebral hemorrhage: a retrospective single-center analysis of 123 cases. Acta Neurochir 160: $1737-1747$

20. Hoff JT (2003) Editorial comment-international variations in surgical practice for spontaneous intracerebral hemorrhage. Stroke 34: $2597-2598$

21. Juvela S, Heiskanen O, Poranen A, Valtonen S, Kuurne T, Kaste M, Troupp H (1989) The treatment of spontaneous intracerebral hemorrhage. A prospective randomized trial of surgical and conservative treatment. J Neurosurg 70:755-758
22. Kelly AG, Hoskins KD, Holloway RG (2012) Early stroke mortality, patient preferences, and the withdrawal of care bias. Neurology 79:941-944

23. Kelly ML, Sulmasy DP, Weil RJ (2013) Spontaneous intracerebral hemorrhage and the challenge of surgical decision making: a review. Neurosurg Focus 34:E1

24. Kirkman MA, Smith M (2013) Supratentorial intracerebral hemorrhage: a review of the underlying pathophysiology and its relevance for multimodality neuromonitoring in neurointensive care. J Neurosurg Anesthesiol 25:228-239

25. Kirkman MA, Mahattanakul W, Gregson BA, Mendelow AD (2008) The effect of the results of the STICH trial on the management of spontaneous supratentorial intracerebral haemorrhage in Newcastle. Br J Neurosurg 22:739-746 discussion 747

26. Koivunen RJ, Tatlisumak T, Satopaa J, Niemela M, Putaala J (2015) Intracerebral hemorrhage at young age: long-term prognosis. Eur J Neurol 22:1029-1037

27. Kothari RU, Brott T, Broderick JP, Barsan WG, Sauerbeck LR, Zuccarello M, Khoury J (1996) The ABCs of measuring intracerebral hemorrhage volumes. Stroke 27:1304-1305

28. LeRoux PD, Haglund MM, Newell DW, Grady MS, Winn HR (1992) Intraventricular hemorrhage in blunt head trauma: an analysis of 43 cases. Neurosurgery 31:678-684 discussion 684-675

29. Lok J, Leung W, Murphy S, Butler W, Noviski N, Lo EH (2011) Intracranial hemorrhage: mechanisms of secondary brain injury. Acta Neurochir Suppl 111:63-69

30. Mendelow AD, Gregson BA, Fernandes HM, Murray GD, Teasdale GM, Hope DT, Karimi A, Shaw MD, Barer DH, investigators S (2005) Early surgery versus initial conservative treatment in patients with spontaneous supratentorial intracerebral haematomas in the international surgical trial in intracerebral Haemorrhage (STICH): a randomised trial. Lancet 365:387-397

31. Mendelow AD, Gregson BA, Mitchell PM, Murray GD, Rowan EN, Gholkar AR (2011) Surgical trial in lobar intracerebral haemorrhage (STICH II) protocol. Trials 12:124

32. Mendelow AD, Gregson BA, Rowan EN, Murray GD, Gholkar A, Mitchell PM (2013) Early surgery versus initial conservative treatment in patients with spontaneous supratentorial lobar intracerebral haematomas (STICH II): a randomised trial. Lancet 382:397-408

33. Morgenstern LB, Frankowski RF, Shedden P, Pasteur W, Grotta JC (1998) Surgical treatment for intracerebral hemorrhage (STICH): a single-center, randomized clinical trial. Neurology 51:1359-1363

34. Morioka M, Orito K (2017) Management of Spontaneous Intracerebral Hematoma. Neurol Med Chir 57:563-574

35. Mustanoja S, Satopaa J, Meretoja A, Putaala J, Strbian D, Curtze S, Haapaniemi E, Sairanen T, Niemela M, Kaste M, Tatlisumak T (2015) Extent of secondary intraventricular hemorrhage is an independent predictor of outcomes in intracerebral hemorrhage: data from the Helsinki ICH study. Int J Stroke 10:576-581

36. Norrving B (2016) Stroke och TIA: rapport från riksstroke utgiven december 2016; riksstrokes årsrapport 2015 - tia - akut stroke. In: Norrving B (ed). Riksstroke Sweden

37. Pantazis G, Tsitsopoulos P, Mihas C, Katsiva V, Stavrianos V, Zymaris S (2006) Early surgical treatment vs conservative management for spontaneous supratentorial intracerebral hematomas: a prospective randomized study. Surg Neurol 66:492-501 discussion 501-492

38. Patil CG, Alexander AL, Hayden Gephart MG, Lad SP, Arrigo RT, Boakye M (2012) A population-based study of inpatient outcomes after operative management of nontraumatic intracerebral hemorrhage in the United States. World Neurosurg 78:640-645

39. Prasad K, Mendelow AD, Gregson B (2008) Surgery for primary supratentorial intracerebral haemorrhage. Cochrane Database Syst Rev:Cd000200 
40. Satopaa J, Mustanoja S, Meretoja A, Putaala J, Kaste M, Niemela M, Tatlisumak T, Strbian D (2017) Comparison of all 19 published prognostic scores for intracerebral hemorrhage. J Neurol Sci 379: 103-108

41. Socialstyrelsen (2018) Nationella riktlinjer för vård vid stroke: Stöd för styrning och ledning. Socialstyrelsens publikationsservice, Stockholm

42. Steiner T, Al-Shahi Salman R, Beer R, Christensen H, Cordonnier C, Csiba L, Forsting M, Harnof S, Klijn CJ, Krieger D, Mendelow AD, Molina C, Montaner J, Overgaard K, Petersson J, Roine RO, Schmutzhard E, Schwerdtfeger K, Stapf C, Tatlisumak T, Thomas BM, Toni D, Unterberg A, Wagner M, European Stroke O (2014) European Stroke organisation (ESO) guidelines for the management of spontaneous intracerebral hemorrhage. Int J Stroke 9:840-855

43. Svanström S GF, Hodell T (2012) Land- och vattenarealer den 1 januari 2012; Kommuner, län och riket. Land and water areas 1 January 2012. SCB. Stockholm, Sweden

44. Teernstra OP, Evers SM, Lodder J, Leffers P, Franke CL, Blaauw G (2003) Stereotactic treatment of intracerebral hematoma by means of a plasminogen activator: a multicenter randomized controlled trial (SICHPA). Stroke 34:968-974

45. Tobieson L, Rossitti S, Zsigmond P, Hillman J, Marklund N (2018) Persistent metabolic disturbance in the Perihemorrhagic zone despite a normalized cerebral blood flow following surgery for intracerebral hemorrhage. Neurosurgery. https://doi.org/10.1093/ neuros/nyy 1179

46. Tsitsopoulos PP, Enblad P, Wanhainen A, Tobieson L, Hardemark HG, Marklund N (2013) Improved outcome of patients with severe thalamic hemorrhage treated with cerebrospinal fluid drainage and neurocritical care during 1990-1994 and 2005-2009. Acta Neurochir 155:2105-2113
47. Vanneste J, Augustijn P, Tan WF, Dirven C (1993) Shunting normal pressure hydrocephalus: the predictive value of combined clinical and CT data. J Neurol Neurosurg Psychiatry 56:251-256

48. Wang KY, Wu CH, Zhou LY, Yan XH, Yang RL, Liao LM, Ge XM, Liao YS, Li SJ, Li HZ, Gao LL, Lin JS, Huang SY (2015) Ultrastructural changes of brain tissues surrounding hematomas after intracerebral hemorrhage. Eur Neurol 74:28-35

49. Webb AJ, Ullman NL, Morgan TC, Muschelli J, Kornbluth J, Awad IA, Mayo S, Rosenblum M, Ziai W, Zuccarrello M, Aldrich F, John S, Harnof S, Lopez G, Broaddus WC, Wijman C, Vespa P, Bullock R, Haines SJ, Cruz-Flores S, Tuhrim S, Hill MD, Narayan R, Hanley DF (2015) Accuracy of the ABC/2 score for intracerebral hemorrhage: systematic review and analysis of MISTIE, CLEARIVH, and CLEAR III. Stroke 46:2470-2476

50. Ziai W, Carhuapoma JR, Nyquist P, Hanley DF (2016) Medical and surgical advances in intracerebral hemorrhage and intraventricular hemorrhage. Semin Neurol 36:531-541

51. Ziai W, Nyquist P, Hanley DF (2016) Surgical strategies for spontaneous intracerebral hemorrhage. Semin Neurol 36:261-268

52. Zuccarello M, Brott T, Derex L, Kothari R, Sauerbeck L, Tew J, Van Loveren H, Yeh HS, Tomsick T, Pancioli A, Khoury J, Broderick J (1999) Early surgical treatment for supratentorial intracerebral hemorrhage: a randomized feasibility study. Stroke 30: 1833-1839

Publisher's note Springer Nature remains neutral with regard to jurisdictional claims in published maps and institutional affiliations. 